\title{
Key roles of government in genomics and proteomics: A public health perspective
}

Allan S. Noonan, MD, MPH

\begin{abstract}
This paper is based on the presentation of Dr. Allan Noonan at the third biennial Asan-Harvard Medical International Symposium on "Genomics and Proteomics: Impact on Medicine and Health" that took place in Seoul, Korea, July 3-4, 2001. Dr. Noonan is a senior advisor to the Surgeon General of the United States and was representing the then Surgeon General, Dr. David Satcher. In this final presentation of the symposium, Dr. Noonan reviews the key roles of government in US health care and discusses several areas where genomic- and proteomic-based information will necessitate changes in the functions of public health. In particular, Dr. Noonan discusses the need for appropriate training to meet the challenges of the genomic future; for sensitivity in the development of policies to address the ethical, legal, and social implications of genomic information; and for dissemination of genomic information to both the professionals and the public. Dr. Noonan concludes with a vision of the genomic future of the next 30 years and a reiteration of the need for partnership among health professionals, educators, and social services professionals. Genet Med 2002:4(6, Supplement):72S-76S.
\end{abstract}

Key Words: public health, US government, genomics, proteomics

Dr. David Satcher sends his apologies for being unable to attend and participate in this exciting and important symposium. As his representative, let me take a moment to describe his role in health in the United States. The Surgeon General of the United States is seen as the nation's number one doctor. He therefore has a lead role in detailing current health policy and future directions. ${ }^{1}$ By negotiating differences of opinion regarding policy in health care, he is, in fact, the national leader in public health.

As a senior advisor to the Surgeon General and a public health provider with years of experience in genetics in public health, I am excited about the progress made since I directed a genetics program several years ago. The presentations in this symposium indicate that genetics, genomics, and proteomics have come a long way, have a long way to go, and are in the hands of very capable people.

In concluding this very exciting symposium, permit me to review the meaning of public health. The core functions of public health are assessment, policy development, and assurance. ${ }^{2}$ Public health is responsible for monitoring the health of the population; informing, educating, and empowering the population to achieve its best health status; mobilizing community partnerships; and developing health policies. A great deal of work will need to be done in the coming days, weeks, and years to develop policies based on the new information

From the Office of Surgeon General, Department of Health and Human Services, Rockville, Maryland.

Allan S. Noonan, MD, MPH, Senior Advisor, Office of Surgeon General, Department of Health and Human Services, 5600 Fishers Lane, Rockville, MD 20857.

DOI: 10.1097/01.GIM.0000043819.54099.D6 that has been brought to us through the Human Genome Project.

The need to make changes in the legal foundation of our health services is immediate. These changes will result from the findings and analyses of public health professionals. Changes in the health workforce are another immediate need that is emphasized by the impact of the Human Genome Project. To support the needs of the US population in terms of genetic health care, prevention, and treatment, an appropriate workforce must be put into place. ${ }^{3}$

Distribution of resources in health remains a large problem. Most resources are currently expended on treatment, with prevention a far second. Evaluation is another area that does not receive its fair share of health resources. The implications and impact of most health expenditures are largely unmeasured. Therefore, focusing on prevention and evaluation, no matter what population is served, is a major public health responsibility and one in which the participants in this symposium must play an active role.

\section{Recent progress in public health}

While the foci of this third biennial Asan-Harvard Medical International Symposium are genomics and proteomics, it would be helpful to review some of the giant steps made in public health in the United States recently.

As the profession responsible for guiding national health priorities and setting outcome standards, in the year 2000, public health published the third 10-year health agenda for the United States titled "Healthy People 2010." 4 The agenda is a set of 10-year objectives for the health outcomes of the US population. The specific objectives are designed to provide the na- 
tion with measures by which to gauge progress in health outcomes during this 10-year period. Most importantly, these objectives are designed to provide states, communities, and providers with a foundation upon which to set their own priorities and measure their own success in improving health outcomes. The first such 10-year agenda was put forward in 1980 . Since that time, the number of objectives has grown from 15 to 467.

Since it is very difficult to keep track of 467 objectives, 10 major public health issues have been selected to provide an ongoing indication of success. These are the 10 Leading Health Indicators (Fig. 1). Genetics plays a major role in approximately half of them. However, of the total 467 objectives, only 1 deals specifically with genetics. Objective 16-20 (Fig. 2), newborn screening and follow-up activities, is a developmental objective with no numerical outcome at this time. Therefore, for all of the action in planning for US health for the next 10 years, and although many of the objectives have genetic implications, it will be very difficult to measure progress in genetics because only one objective will provide a direct measure of the advances discussed in this symposium.

\section{Genomics and proteomics in public health}

Many genomics- and proteomics-related questions must be addressed in this decade. For instance, the standards for screening newborns differ from state to state. Should there be national standards? ${ }^{5}$ If so, what should these standards be, and how can they be developed? What would be appropriate guidelines for the prevention and early detection of a wide variety of genetic diseases? How will the growing need for recommendations about appropriate specific actions, such as screening women for Factor V Leiden, be met?

The discoveries in genomics and proteomics will result in a broad spectrum of products-from diagnostic equipment and tests to preventive strategies and treatment therapies, includ-

\section{Leading Health Indicators}

Ten Major Public Health Issues

- Physical activity

- Overweight and obesity

- Tobacco use

- Substance abuse

\section{- Responsible sexual} behavior

Fig. 1 Healthy People 2010: The Leading Health Indicators, 10 Major Public Health Issues.

\section{Healthy People 2010 Newborn Screening Objectives}

16-20. (Developmental) Ensure appropriate newborn bloodspot screening, followup testing, and referral to services.

16-20a. Ensure that all newborns are screened at birth for conditions mandated by their State-sponsored newborn screening programs, for example, phenylketonuria and hemoglobinopathies.

16-20b. Ensure that followup diagnostic testing for screening positives is performed within an appropriate time period.

16-20c. Ensure that infants with diagnosed disorders are enrolled in appropriate service interventions within an appropriate time period.

Fig. 2 Healthy People 2010: Newborn Screening Objectives.

ing gene therapy and designer drugs. Development and implementation of strategies for the appropriate use of these products will be very time-consuming. One of the realities of public health in the United States is that it is dependent upon an intertwined bundle of bureaucracies, and time is always the enemy of bureaucracy. As genomics and proteomics expand, this constraint will become more severe when implementing beneficial services. In addition, the difficulty of developing consensus on ethical, legal, and social issues will add to the major time challenges.

The Secretary of Health and Human Services has put forth a mandate that genetic testing be safe and that effective genetic technologies resulting from future research be made accessible to the public as promptly as possible. Executing this mandate is the responsibility of public health. It must adopt the overarching principles of the Genetic Testing Advisory Committee that the public be best served by appropriate oversight of the development of genetic tests and that the public be involved in an ongoing manner in the consideration of genetic testing issues. As previously stated, public health has a key role in genetic education and in developing the foundation for federal legislation to prohibit genetic discrimination. Genomics and proteomics will henceforth be integral to many of the functions of public health.

\section{Training for the genomic future}

An area of public health that is particularly exciting is the development of the capacity to provide preventive services. To further this end, the Centers for Disease Control and Prevention (CDC) has cooperative agreements with three US schools of public health to train public health workers in genetics, genomics, and proteomics. ${ }^{7}$ In the near future, the public health workforce will include experts who understand genomics and proteomics and who can use this knowledge to achieve goals in genomics and proteomics that are consistent with the public health perspective.

While training for physicians, nurses, and other clinical providers is planned, training for program administrators, educa- 
tors, and counselors has already been initiated. Since social workers play a key role in so much of what is done in genetic diseases, and indeed in all health care, their training needs must be met as must those of laboratory staff and environmental professionals. Career development is key to the training of all of these professionals. It is essential that there be well-thoughtout strategies to assure the training of the entire health workforce in genetics prevention and treatment. To this end, the $\mathrm{CDC}$ is also working with the teachers of preventive medicine. In addition, its Epidemic Intelligence Service program now has specific roles for its incoming enrollees in genomics. The issue of career development is being taken seriously, and many effective efforts are under way. ${ }^{8-10}$

Another primary concern of public health is the person who is working at the community level. With the assistance of many of the experts who have participated in this symposium, the US Department of Health and Human Services (HHS) is developing materials to define genomics and proteomics and outline essential services. Examples of best practices in genomics and proteomics in public health are being developed and distributed widely, as are guidelines for future activities.

In the area of infrastructure, the HHS is working to strengthen newborn screening and to improve the linkages between our genetics and public health programs. The HHS is also focusing on the ethical, legal, and social implications of these programs. ${ }^{11}$ Genetic literacy for all involved is a funded priority. Current educational efforts focus not only on genetics health professionals, but also on primary care professionals.

In the United States, nurse practitioners, genetic counselors, and nurse midwives are playing an ever-expanding role in primary care. It is very important that in planning the training of health professionals we consider those with the time, expertise, and sensitivity to sit down with clients and their families to explain complex genetic diseases. The fears and possible misconceptions of the clients must be understood and assistance given during the making of appropriate decisions.

\section{Disseminating genomic information}

Disseminating genomic information is a major responsibility of public health, and it has been accomplished in a number of ways. The CDC's Office of Genomics and Disease Prevention (OGDP) publishes a weekly genetics and prevention document that is distributed to a wide range of health professionals in the United States. ${ }^{12}$ The OGDP also publishes a genomicbased monthly series on the Internet ${ }^{13}$ and maintains a human genetics information exchange network, the Human Genome Epidemiology Network (HuGENet ${ }^{\mathrm{TM}}$ ), a Web site where people can log on, share information, gather information about problems they are experiencing, and provide support for one another. ${ }^{14}$

The Surgeon General's publications are another potential mechanism for disseminating genomic information. ${ }^{15}$ As the number-one spokesperson for health in the country, the Surgeon General spends a great deal of time on publications that cover a wide variety of issues, including tobacco use, oral health, and obesity-all major public health problems in the United States. Such publications are very effective. For instance, in 1999, the Surgeon General published a report on mental health that has begun to change the approach to mental health in the United States. ${ }^{16}$ In the future, the Surgeon General will play a major role in assuring the most effective use of genomic and proteomic knowledge. As the mysteries of genomics are unveiled, the Surgeon General's publications will be very useful in informing both professionals and the public about scientifically based consensuses regarding the diagnosis, treatment, and prevention of genetic illnesses.

\section{Ethical, legal, and social implications}

\section{Ethical}

Genomics and proteomics will expand the availability of an individual's most personal information. The dilemma of how to use this information in the most principled manner will be a challenge to individuals, providers, institutions, and government. Since moral values vary with family, community, and culture, government is in the difficult position of determining the ethical standards for its own functions, and promoting adherence to ethical principles within its sphere of influence.

Eugenics, sometimes referred to as the "science" of improving hereditary qualities, is a difficult issue for public health. In the United States, some have seen the restriction of immigration of specific populations as eugenics. ${ }^{17,18}$ And laws in practice until recently allowed the involuntary sterilization of individuals deemed to have mental "defects." With our rapidly expanding knowledge of genomics and proteomics, today we must be careful when describing the characteristics of individuals and population groups. True, genetics is the basis for behaviors, disabilities, and intelligence in some syndromes, but much more research needs to be done on its role in these characteristics. When making new genomic policies, we must always remember that eugenics is not only part of our recent history, but without vigilance it could return to be part of our present and future. Inevitably, advice and policies dealing with reproduction and genetics will be perceived by some as eugenics. Hence extreme caution must be exercised in the development of these policies.

\section{Legal}

As government determines its role regarding the ethical, legal, and social implications of these new practices, it will logically play a role in the prevention of stigmatization and discrimination. Public health and government are in a unique position to educate all of society regarding these injustices and to safeguard individuals from discrimination in their occupations, health insurance, and other areas because of their genetic makeup. Health information must not be used for harm.

The fact that states are increasingly putting laws that proscribe genetic discrimination into place documents the very real concern about genetic discrimination in the United States. Notably, 1997 was a boom year for states enacting antidiscrim- 
ination laws based on genetically derived information. But this legal action is not only happening at the state level. At the federal level, there are several pieces of legislation pending that address the questions of genetic discrimination.

As mentioned previously, the workplace is another site of activity focusing on the future of genetics. In the United States, employers are often the providers of health care. (According to US Department of Labor figures for 1992-93, 88\% of full-time employees in private establishments were offered health care plans by their employers. ${ }^{19}$ ) Employers therefore may sometimes possess information pertaining to the genetic makeup of workers and so could be in a position to use that information in their own interests. ${ }^{20-22}$ This may not be in the best interest of the worker. Health insurance and workmen's compensation for disability are areas where genetics' problems are tied closely to employment and are areas that may rely on the judgment of an employer, and sometimes of a third party.

In 1998, there was a boom in legal action at the state level in response to genetic discrimination in the workplace. At the federal level, there was an Executive Order in February 2000 to prohibit discrimination based on genetic information in federal employment.

The courts, too, are wrestling with the consequences of genetic-based information. In addition to discrimination, courts are dealing with a range of issues that relate to unequivocal genetic identification, such as paternity and management of individuals whose violence is part of a genetic syndrome. Consequently, the courts are playing a major role in the relationship of genetics and society. Or perhaps it is the other way around: genetics is playing a major role in court decisions. Hence the need for expertise in genomics and proteomics in our court system can be expected to grow.

While being careful not to present themselves as legal experts, public health providers will need to be knowledgeable about legal implications and issues as they arise, so that they can guide individuals to those who can appropriately address legal questions when necessary. Public health providers will also need to know of existing safeguards and their effectiveness so that they can document problems pertaining to genomics. This will be a key function of public health. While there are benefits to increased genetic information, there are also risks.

When informing individuals, public health providers must keep in mind that the population is very skeptical about the use of genetic information. In a June $2001 \mathrm{CNN}$ poll, $46 \%$ of the Americans queried felt that the Human Genome Project was going to be harmful. And when asked, "Would you want genetic information about future disease-risk?" only $46 \%$ said they would. We need to remember that physicians and patients often have differing points of view on this issue.

\section{Over the horizon}

Based on human genomics and proteomics, leaders of the Human Genome Project at the NIH have cited some exciting predictions for the future of health care. By 2010, there will be predictive genetic tests for a dozen conditions and preventive interventions for several of them. Many primary care providers will practice genetic medicine and there will be some "reasonably effective" legislative solutions to the problems of discrimination and privacy.

By 2010, most of the problems of preimplantation diagnosis will have been resolved, although this advance will undoubtedly result in intensification of ethical debates already under way.

Access to services in 2010 will remain inequitable, especially in the developing world, but most likely this will remain true in the United States. Most of the procedures reviewed in this symposium are expensive and will continue to be expensive. Many require the skills of highly trained genetics professionals, whose numbers will remain insufficient in 2010 .

By 2020, gene-based designer drugs for diseases such as diabetes and hypertension are expected to be available, and genomics and proteomics will play key roles in individualized therapies for many illnesses. Cancer therapy will be based on the genetic identity of the tumor, and there will be major transformations in the diagnosis of mental illnesses based on genetics.

By 2030, comprehensive genomics-based health care will be the norm. Much of what has been discussed at this symposium will be the foundation for the "new medicine" 30 years hence. Preventive medicine will be individualized. Causal environmental factors will have been pinpointed for many diseases, and our laboratories will have access to complete models of many human cells. It is projected that the average life span for the US population will be 90 years, with genomics and proteomics contributing greatly to the increase.

But when dealing with the information realized by genomics and proteomics, it is crucial to remember that this information is different from the health information that we've talked about in the past. Genomic-based information is very personal, has the power to harm through discrimination, and is potentially predictive. It can involve more than the individual patient. Furthermore, it is permanent information with lifelong pertinence. With all this for background, today it is understandably very difficult to list the key roles of government. The differing needs and differing perspectives of societies will have a major impact on the priorities of each government, and the list of options will continue to expand for decades at least. This, however, does not negate the need for planning. On the contrary, planning must be seen as the most immediate key role of government. One major principle of public health is that society must plan today for the health realities 10 years hence. But as discussed, genetics has not yet received its appropriate place on the drawing boards for the health reality of the United States.

Access. Equity. Quality. The workforce. All are the key responsibilities of the US government working closely with state and private partners. But even with all these health responsibilities and a strong partnership network, the benefits of the Human Genome Project cannot be realized without the strong support of the government in the areas of education, social services, and protection from discrimination. Those of us who 
work in health and who understand genomics must join hands with our partners in education to develop strategies to integrate genetic information into basic education. And as well as organizational education, there must personal education and accountability. We must join hands with our social services partners to ensure that genetic diseases are treated in a socially appropriate manner. We must work with legal and justice entities to ensure that the changes resulting from this effort are beneficial to all. There is much to be done.

The unraveling of the basics of the human genome has taken us to the top of a hill. As we look out from this new vantage point, we see many paths leading from this hill to the horizon: a preventive health path, a medical diagnosis and treatment path, a legal path, a social path, and, most importantly, an ethical path. These paths go over the horizon to the state of healthy human genomics and proteomics. For us to reach that state, the paths must come together so that all of the information - all of the actions - can be used collaboratively and compassionately and the health of the people in that state can be "the best that it can be." On behalf of Dr. Satcher and myself, it has been an honor to participate in this groundbreaking symposium.

\section{Acknowledgments}

The author thanks his colleagues in the various government agencies whose work contributed to the content of this presentation. He especially thanks Francis S. Collins, Director of the National Human Genome Research Institute of the National Institutes of Health; Michele A. Puryear, Chief of Genetic Services of the Health Resources and Services Administration of the Department of Health and Human Services; and Paula W. Yoon, staff scientist at the Office of Genetics and Disease Prevention of the Centers for Disease Control and Prevention.

\section{References}

1. Office of the Surgeon General, 2002. http://www.surgeongeneral.gov/sg/duties.htm.
2. Institute of Medicine. The future of public health. Washington, DC: National Academy Press, 1988

3. Public Health Functions Project. Report. The public health workforce: an agenda for the 21st century, 2002. http://www.health.gov/phfunctions/

4. US Department of Health and Human Services. Healthy people 2010, 2002. http:// www.health.gov/healthypeople/document/

5. HRSA Maternal and Child Bureau, Genetic Services Branch, University of Texas Health Science Center at San Antonio. The National Newborn Screening and Genetics Resource Center, 2002. http://genes-r-us.uth.scsa.edu/

6. Vandenbroucke JP, van der Meer FJ, Helmerhorst FM, Rosendaal FR. Factor V Leiden: should we screen oral contraceptive users and pregnant women? BMJ 1996; 313:1127-1130.

7. CDC Genomics and Disease Prevention. Centers for Genomics and Public Health 2002. http://www.cdc.gov/genomics/activities/fund2001.htm.

8. HRSA Bureau of Health Professions. Public Health, 2002. http://bhpr.hrsa.gov/ publichealth/index.htm.

9. CDC Genomics and Disease Prevention. Training and education, 2002. http://www.cdc.gov/genomics/training.htm.

10. HRSA Maternal and Child Health Bureau and the Bureau of Health Professionals. Genetics in primary care, 2002. http://bhpr.hrsa.gov/medicinedentistry/genpc.html.

11. US Department of Energy. Human Genome Project information: ethical, legal, and social issues (ELSI), 2002. http://www.ornl.gov/hgmis/elsi/elsi.html

12. CDC Office of Genomics and Disease Prevention. Genomics Weekly Update, 2002 http://www.cdc.gov/genomics/update/current.htm.

13. CDC Office of Genomics and Disease Prevention. Public Health Perspective Series 2002. http://www.cdc.gov/genomics/info/perspective.htm.

14. CDC Office of Genomics and Disease Prevention. The Human Genome Epidemiology Network (HuGENet), 2002. http://www.cdc.gov/genomics/hugenet/ about.htm.

15. DHHS Office of the Surgeon General. Publications, 2002. http://www.surgeon general.gov/library/default.htm.

16. The US Surgeon General. Mental health: a report of the Surgeon General. Rockville, MD: Office of the US Surgeon General, 2002. http://www.surgeongeneral.gov/library/mentalhealth/home.html.

17. Varma JK. Eugenics and immigration restriction: lessons for tomorrow. JAMA 1996; 275:734, 737 .

18. Allen GE. The social and economic origins of genetic determinism: a case history of the American Eugenics Movement, 1900-1940 and its lessons for today. Genetica 1997;99:77-88.

19. Eberhardt MS. Health, United States, 2001. Washington, DC: US Department of Health and Human Services, Centers for Disease Control and Prevention, Nationa Center for Health Statistics, 2001.

20. McCunney RJ. Genetic testing: ethical implications in the workplace. Occup Med 2002;17:665-672.

21. Goldberg IV. Genetic information privacy and discrimination. Health Care Manag (Frederick) 2001;20:19-28.

22. Schill AL. Genetic information in the workplace: implications for occupational health surveillance. AAOHN J 2000;48:80-91. 